\title{
EDUCACIÓN ARTÍSTICA EN CHILE: FERNANDO ALVAREZ DE SOTOMAYOR, JUAN FRANCISCO GONZÁLEZ Y PABLO BURCHARD, TRES MAESTROS EMBLEMÁTICOS:
}

\section{PEDRO EMILIO Zamorano PÉREZ**}

\section{RESUMEN}

Este artículo está referido a la educación artística en Chile. Entrega información diversa acerca de los modelos estéticos y metodológicos seguidos en el país, desde la creación de la Academia de Pintura, en 1849, hasta el ecuador del siglo XX. Analiza algunas claves endógenas que operan al interior de la Escuela de Bellas Artes, tales como maestros, liderazgos, discípulos, debates, etc. De otra parte, ilustra acerca de las vinculaciones de la Escuela con otros actores que influyen en la actividad cultural del país: estado, circuitos de difusión, crítica, entre otros. El trabajo se centra en el aporte de tres figuras emblemáticas de la primera mitad del siglo XX, cuya docencia marcó con su sello a un conjunto importante de artistas nacionales: Fernando Alvarez de Sotomayor, Juan Francisco González y Pablo Burchard.

Palabras claves: Educación artística en Chile, modelos y teorías, maestros emblemáticos.

\section{ABSTRACT}

This article makes reference to artistic education in Chile. It provides diverse information about the aesthetic models and methodologies followed in the country, from the creation of the Academia de Pintura (Painting Academy) in 1849 up to the middle of the twentieth century. It analyzes some key elements that operated within the Escuela de Bellas Artes (School of Fine Arts) such as masters, leadership, disciples, debates, etc. As well, it illustrates the links between the school and other actors involved in the cultural activity in the country: the State, publicity circuits, and criticism, among others. The paper is centered on the contribution of three emblematic figures of the first half of the twentieth century whose teaching left its distinctive mark on a large number of national artists: Fernando Alvarez de Sotomayor, Juan Francisco González and Pablo Burchard.

Keywords: Artistic education in Chile, models and theories, emblematic masters.

Recibido: 20.11.2006. A probado: 23.05.2007.

* Este trabajo corresponde al Proyecto "Asedio exógeno a la pintura chilena: 1920-1960", Fondecyt $\mathrm{N}^{\circ} 1040858$.

** Dr. en Historia del Arte, Instituto de Estudios Humanísticos Abate Juan Ignacio Molina, Universidad de Talca. Talca, Chile.E-mail: pzamoper@utalca.cl 
L A NACIENTE sociedad del Chile postcolonial tuvo que darse una estructura, un orden social y cultural, en ámbitos en donde estaba todo por hacerse. En el terreno de las artes, el país necesitaba formar a sus pintores y escultores. En 1849, bajo el gobierno de Manuel Bulnes, se crea la Academia de Pintura ${ }^{1}$. Su fundación fue un hecho de gran trascendencia, ya que marca el inicio de la enseñanza artística en el país bajo una estructura académica. Aun cuando sus primeros maestros extranjeros encauzaron su enseñanza en la referencia de esquemas metodológicos bastante tradicionales, su aporte fue significativo para la emergente pintura nacional. Permitió entregar una formación artística sistematizada, dotó a los alumnos de conocimientos prácticos y teóricos, y generó un quehacer apropiado para la creación y el diálogo cultural. Por primera vez se otorga en el país la posibilidad de una formación artística estructurada en programas académicos, con profesores de buen nivel y con el respaldo del Estado.

La Academia reeditó en Chile los antiguos modelos de las academias oficiales europeas, de corte neoclásico. Más que una estructura administrativa, se trataba de una concepción ideológica, ya que anidaba en su corazón el peso de la tradición neoclásica europea. Ello, entre otras cosas, por las convicciones estéticas de sus primeros directores, por los modelos formales e iconográficos que se promueven y por la continuidad de estudios en Europa (principalmente París) de muchos de sus egresados. Cosme San Martín

${ }^{1}$ El 4 de enero de 1849, con las firmas del Presidente de la República Manuel Bulnes y del ministro Salvador Sanfuentes se decretó la creación de la Academia de Pintura, cuya inauguración se realizó el 7 de marzo siguiente. La recién creada Academia se ubica en el segundo piso del Congreso Nacional de la época. El primer director de la entidad fue el pintor italiano Alejandro Cicarelli (18101879), artista formado en la escuela neoclásica. El acento tradicional queda ya claramente definido en sus planes y programas de estudios. No cabe duda que, desde sus inicios, la Academia de Pintura tuvo por principios, en lo que se refiere a argumentos plásticos y simbólicos, las normas de la cultura grecorromana. El modelo de las academias europeas, francesas e italianas principalmente, fue tomado al pie de la letra en nuestro país. El segundo director de la entidad fue el alemán Ernesto Kirchbach (1832-1880), un pintor de temas literarios, de fábulas y leyendas, que poco flexibilizó los dogmas pedagógicos que había impuesto su predecesor. A este artista sucedió en el cargo el pintor italiano Juan Mochi (1831-1892), cuya docencia resultó más acorde a las inquietudes de los jóvenes alumnos del plantel. El artista abrió su propuesta pedagógica hacia temáticas costumbristas e históricas.

En 1854 la Academia se fusiona con las cátedras de Escultura y Ornamentación, denominándose a partir de ese momento como Academia de Bellas Artes. En 1858 pasa a depender de la Sección Universitaria del Instituto Nacional. Posteriormente, con la promulgación del Estatuto Orgánico de 1879, la Universidad de Chile crea la nueva Facultad de Filosofía, Humanidades y Bellas Artes, bajo cuya tutela quedará la Academia de Bellas Artes, que pasa a denominarse ahora Escuela de Bellas Artes.

Después de la Guerra Civil de 1891, la Escuela de Bellas Artes es trasladada a un local ubicado en la calle Maturana 750 en donde permanece hasta 1910, cuando es instalada en el recién inaugurado Palacio de Bellas Artes, ubicado en el Parque Forestal.

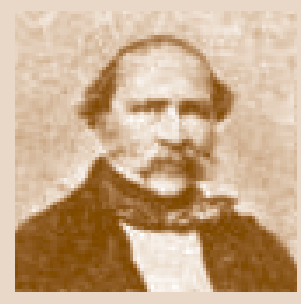

A. Cicarelli

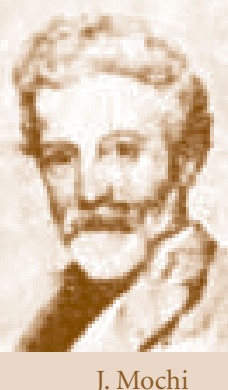

J. Mochi 
(1850-1906), Pascual Ortega (1839-1899), Abraham Zañartu (1835-1885), José Mercedes Ortega (1856-1900), Ernesto Molina (1857-1904), entre otros, encabezan una nómina mucho más extensa.

En los inicios de la enseñanza de las artes en el país hubo un importante apoyo del Estado. El sector oficial -léase Estado y sociedad influyente- respaldó estas actividades, pero también tuvo tribuna y opinión estética. Este modelo clásico fue validado por la oficialidad política y social, actores que encauzan su opinión a través de algunas organizaciones de carácter participativo, que apoyan el desarrollo cultural local. Entre ellas la Sociedad Artísti$\mathrm{Ca}^{2}$, fundada en 1867; la Comisión Permanente de Bellas Artes, y el Consejo Superior de Artes y Letras ${ }^{3}$, entidad esta última creada en los inicios del siglo XX y que presidía el propio ministro de Instrucción Pública. El Consejo tenía a su cargo la "vigilancia general" de todos los establecimiento públicos de enseñanza artística del país ${ }^{4}$. El fomento del "buen gusto estético" fue una de las prerrogativas más importantes de este Consejo. Un buen gusto que debemos entender asociado a ciertos principios formales e iconográficos y a una crítica que legitimaba al arte nacional desde una mirada europea y academicista. El Estado tuvo también una fuerte presencia en la organización de la Exposición Internacional de 1910. Este certamen, de un claro trasfondo diplomático, fue manejado directamente por el Consejo de Bellas Artes, razón por la cual se privilegiaron en la conformación de las distintas comisiones, que actuaron tanto en Chile como en el extranjero, criterios tradicionales y académicos ${ }^{5}$.

Como es posible apreciar, las responsabilidades que el Gobierno había asumido sobre las bellas artes tuvieron un alcance mucho mayor que el sólo financiamiento de sus planteles de enseñanza. El Gobierno pesó siempre con su visión, hizo valer y con fuerza su opinión (a través precisamente de su facultad discrecional de financiamiento) sobre el complejo mundo de ideas estéticas que la enseñanza y difusión esta disciplina comportaba. Un Estado militante, ordenador y con un fuerte acento tradicionalista respecto de sus manifestaciones culturales. Eso, hasta bien adentro del siglo XX.

\footnotetext{
${ }^{2}$ Fue fundada por Pedro Lira y Luis Dávila Larraín, incorporando además artistas, aficionados y coleccionistas. Dentro de sus principales realizaciones cuenta la creación del Primer Museo de Bellas Artes, inaugurado en 1880.

${ }^{3}$ Creado mediante decreto el 31 de mayo de 1909.

${ }^{4}$ También le correspondía la supervigilancia y la dirección de la Escuela de Bellas Artes. Sus prerrogativas eran, desde luego, establecer las políticas y orientaciones, pero, además, podía dictar o modificar los planes de estudio y reglamentos internos de los diversos establecimientos artísticos; proponer al Gobierno el nombramiento de sus directores; nombrar o remover a los profesores y empleados; determinar las pruebas que debía exigirse a los alumnos "que aspiren al título de idoneidad profesional" y expedir los mismos títulos.

${ }^{5}$ A decir de Patricio Lizama Améstica (1992): "La famosa exposición del Centenario en 1910 fue el paradigma de la hegemonía del arte académico. El Consejo de Bellas Artes -integrado en su mayoría por personalidades de la vida pública- la organizó, seleccionó los invitados, presidió los jurados de las diferentes secciones de la exposición y escogió las obras que se compraron para el Museo Nacional".
} 
La Escuela y el Consejo de Bellas Artes monopolizaron en las primeras décadas del siglo XX el escenario de las artes visuales en el país, validando un modelo estético al cual adhieren amplios sectores de la cultura nacional. En el plano de la enseñanza artística, este modelo imponía a alumnos y profesores una rigurosa disciplina pedagógica y un repertorio formal e iconográfico que hundía su mirada en el pasado grecorromano. El paradigma caracterizó la obra de casi la totalidad de los artistas formados en la Escuela hasta los años iniciales del siglo $\mathrm{XX}^{6}$.

Hablamos de un modelo que define con su sello la crítica de arte, los circuitos de difusión y las decisiones de los estamentos oficiales.

El perfeccionamiento de los alumnos más aventajados en el extranjero fue parte de una política institucional. Estudiar en Europa, léase Francia, significaba poner al alcance de nuestros artistas las raíces de la gran cultura; hacerlos "conocer" el gran mundo. Francia era mirada como un modelo de cultura e ilustración. Allí los pintores nacionales tuvieron por maestros a: Alexandre Cabanel ${ }^{7}$, Jean Paul Laurens ${ }^{8}$, Jean León Gérome ${ }^{9}$, Fernand Cormon $^{10}$ y Juan Antonio González ${ }^{11}$, entre otros. Es decir, algunas de las figuras más relevantes de la tradición neoclásica-romántica, vinculados a los seguidores de Ingres, David y Delacroix. El historiador español Antonio Romera, radicado por largos años en nuestro país, advierte al influjo francés como un persistente modelo cultural para nuestro país. El buen gusto, los refinamientos sociales, pasaban necesariamente por la moda, el arte, la arquitectura y, prácticamente, todas las formas de expresión cultural francesa. De este modo las raíces culturales hispanas, tan definitorias durante la Colonia, se sumieron, al menos en el dominio del arte, en un profundo olvido.

\footnotetext{
6 "El perfil inconfundible de esa formación define a un nutrido grupo de pintores nacionales, y en sus obras se aprecia reiterativamente ciertas constantes comunes: el rigor lineal con que trabajan la superficie de la tela, modelando y encerrando los contornos, para lograr la máxima objetividad de las formas; en estrecho maridaje con ese trabajo lineal, el color se somete y se subordina a los imperativos que surgen de las cualidades colóricas propias de los seres y de los objetos reales. Las telas así realizadas resultan ser -la mayoría de las veces-formas frías, casi sin vida" (Ivelic y Galaz, 1981: 82).

${ }^{7}$ Alexandre Cabanel (1823-1889), pintor de historia, composiciones mitológicas, religiosas y decorativas. Obtuvo el Premio Roma en 1845, honor que significó su consagración como pintor académico.

${ }^{8}$ Jean Paul Laurens (1838-1921), pintor de historia, composiciones religiosas, retratos, paisajes, cartones para tapices, acuarelista, escultor e ilustrador. Destacado artista, fue profesor de la Academia de Tolouse y la Academia Julian.

${ }^{9}$ Jean León Gérome (1824-1904), pintor de historia, mitologías, retratos y paisajes. Vinculado a las academias oficiales francesas del siglo XX y a la corriente neoclásica. Fue un ferviente admirador de la tradición grecorromana.

${ }^{10}$ Fernand Cormon (1854-1924), pintor de historia, composiciones religiosas, personajes típicos, animales y flores. Fue profusamente laureado en los salones oficiales franceses.

${ }^{11}$ Juan Antonio González (1842-1914), español, pintor de género, retratos y grabador. Realizó sus actividades artísticas en Francia y España.
} 


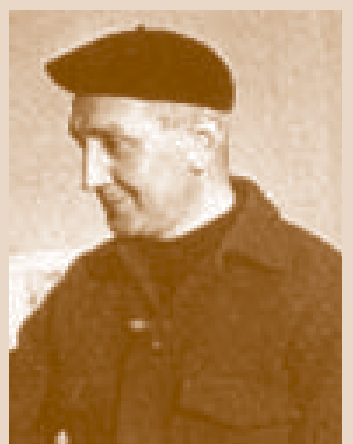

L. Vargas Rosas

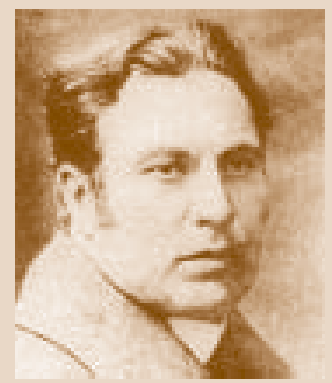

J. Ortiz de Zárate
La filiación de lo francés, o lo europeo en general, fue entendida por la crítica nacional como un argumento plausible: un juicio de valor en sí mismo. Se le valoraba por entender que provenía de una cultura más avanzada, además como una expresión de modernidad y sintonía con el mundo. No había espacios, o éstos eran muy restringidos, para perfilar un arte con signos y una cierta identidad nacional. Esta situación hizo víctima de una marcada relegación a los pintores de 1913, quienes habían optado por una temática de perfiles costumbristas.

\section{LA CRISIS DEL MODELO CLASICO}

En el mes de junio de 1923, en la Casa de Remates "Rivas y Calvo" de Santiago, se presenta una primera exposición de un grupo de pintores que plantean un cambio (o quiebre) más o menos definitivo con las tradiciones académicas imperantes en la plástica nacional. Se trata del grupo Montparnasse ${ }^{12}$, nombre de varios artistas chilenos, que residieron en los inicios de los años veinte en París. De vuelta a Chile se unen para manifestar su disconformidad (rebeldía) contra el arte que preponderaba todavía en el país. Simbólicamente se denominaron grupo Montparnasse, poniendo en evidencia su filiación ideológico-estética. La exposición de 1923 produjo asperezas y convulsionó al público y a la crítica oficial. Diarios y revistas de la época se hicieron parte de las polémicas y las controversias que generó la muestra. La mayor parte de estas publicaciones adherían al academicismo todavía imperante en el país. La exposición provocó claras rupturas con la tradición estética dieciochesca, situación que se acentuaría un lustro después, en el Salón de 1928. La posición de los artistas montparnasseanos produjo, por cierto, más reacciones que adeptos, aun cuando contó con el aplauso de algunas figuras emblemáticas de nuestro escenario cultural, entre ellos Juan Francisco González y Alvaro Yáñez Bianchi, más conocido como Jean Emar ${ }^{13}$.

El grupo Montparnasse es el primer testimonio colectivo de modernidad en la historia de la pintura chilena. El arte para ellos será un quehacer del intelecto que rompe con el pasado académico. El ideologismo montparnasseano se propuso para realizar su "quiebre" con el arte tradicional, varias

\footnotetext{
${ }^{12}$ Integran el grupo los pintores Luis Vargas Rosas (1897-1977), Enriqueta Petit (1900-1984), Julio Ortiz de Zárate (1885-1946), Manuel Ortiz de Zárate (1887-1946), Augusto Eguiluz (18931969), José Perotti ((1898-1956), Jorge Letelier (1887-1996), Hernán Gazmuri (1901-1979), Camilo Mori (1896-1973), Waldo Vila (1896-1979) e Isaías Cabezón (1891-1936).

${ }^{13}$ Alvaro Yáñez Bianchi (1893-1964), más conocido como Jean Emar. Regresó de París en 1923, transformándose en activo actor del escenario de nuestra crítica de arte. En las páginas del diario La Nación, de su padre Eliodoro Yáñez, escribió numerosas páginas sobre el arte que representaban los artistas del grupo Montparnasse.
} 
metas; una de ellas, quizá la principal, fue poner en vigencia y práctica las ideas de Paul Cézanne (1839-1906), especialmente aquellas que acuñó el pintor francés en su período de madurez (1880-1886), cuando se apartó de los impresionistas, tratando a la naturaleza bajo una racionalidad estructuralista. Esto lleva al Grupo Montparnasse a oponerse a toda pintura que llevase en sí los estigmas impresionistas y, de manera más decidida, a aquellas propuestas clásicas, románticas o realistas courbetianas ${ }^{14}$. Como hemos de entender, esto significó una fractura absoluta con las tradiciones plásticas establecidas en Chile desde los inicios de la enseñanza del arte.

La innovación artística en Chile -coincidente con el despertar artístico en Latinoamérica que se manifiesta en la década de $1920-30^{15}$ - se desarrolla desde la periferia cultural, al margen de las instancias oficiales, entre las cuales se cuenta la propia Escuela, el Consejo de Bellas Artes y el discurso académico de la crítica. En el país comienza a generarse un debate social y cultural mucho más intenso, que penetra capas culturales más extensas. La hegemonía que habían ejercido algunos grupos socialmente privilegiados comienza a debilitar su liderazgo ante la presencia de otros discursos estéticos y otros referentes sociales. Es el momento del ascenso de los grupos obreros, del proletariado y del acceso de las clases populares a la Escuela de Bellas Artes.

El quiebre, entre aquellos que abogaban por el modelo clásico y aquellos que miraban el arte a partir de su inmanencia estética, se ve agudizado en el polémico Salón de $1928^{16}$. A través de la Revista Ilustrada, se profirieron ácidas críticas a esta muestra. Las voces conservadoras fueron implacables. Ricardo Richon Brunet (1928) señaló:

Se viene falseando la importancia del Salón, que fuera un torneo, para convertirse en un asilo de la indigencia intelectual... El esoterismo artístico constituido por la dirección de la Escuela de Bellas Artes y los intereses que se han creado a su alrededor, más que tolerados, defendidos por los representantes del Ejecutivo, van marcando ya el rumbo hacia el desastre.

\footnotetext{
${ }^{14}$ El código del Grupo Montparnasse se forma con la propuesta de Cézanne, el racionalismo cubista y el desborde cromático de los fauves. Sumemos a todo esto la gran acentuación proyectativa de los sentimientos dados por el expresionismo alemán, que llama especialmente la atención para sus propuestas pictóricas.

${ }^{15}$ Algunos de los grandes movimientos artísticos que se dan en Latinoamérica hacia la década de 1920-30 fueron el movimiento mexicano Manifiesto del Sindicato de Artistas Revolucionarios (1922), la Semana de Arte Moderno de Sao Pablo (1922), el Manifiesto Martinfierrista, aglutinado en torno a la revista M artín Fierro, publicada en Buenos Aires, a partir de 1926, entre otros.

${ }^{16}$ En el Salón de 1928 participó un grupo de artistas, entre los que se encontraban Herminia Arrate, Héctor Banderas, Ana Cortés, Gustavo Carrasco, Jorge Caballero, Héctor Cáceres, Marco A. Bontá, Inés Puyó y María Tupper. La muestra provocó una fuerte crítica de los partidarios de la pintura académica.
} 


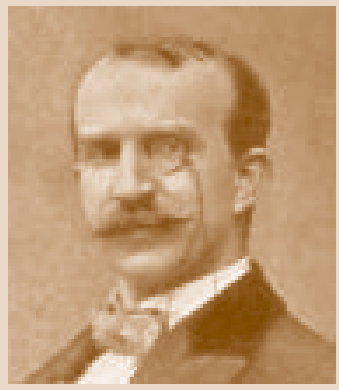

R. Richon Brunet
Richon Brunet ${ }^{17}$, la opinión local más conservadora de la crítica en ese entonces, denuesta a aquellos que se "hunden en el légamo del modernismo", criticando fuertemente a los seguidores de Matisse, Gauguin y, sobre todo, Cézanne, autor este último a quien califica como "rey del bluf". Jorge Letelier (1936), por su parte, comentando el Salón Oficial de Artes Plásticas de ese año, señalaba “... y están en mayoría, aquellos para quienes una naturaleza muerta no es meritoria si todas las leyes de la perspectiva no han sido transgredidas". Las críticas fueron mayoritarias para el Salón de 1928. Sin embargo, hubo voces, como las de Joaquín Edwards Bello, que aplaudieron la exposición. Los desacuerdos y descalificaciones manifestados en el comentado certamen llevan el debate a un punto insostenible. La consecuencia de tales desavenencias fue la intervención del Gobierno del general Carlos Ibáñez del Campo (1927-1931), quien a través de su ministro de Instrucción Pública Pablo Ramírez, decidió cerrar la Escuela de Bellas Artes y enviar a estudiar a Europa a veintiséis de los más destacados alumnos y profesores del plantel ${ }^{18}$. Se mandó, de este modo, a parte importante de los mejores artistas al Viejo Mundo, fijándosele a cada cual un itinerario de perfeccionamiento. Este consideraba el conocimiento de aspectos prácticos, teóricos y metodológicos para la enseñanza del arte, con expresa indicación de los países en que se debían cursar los estudios. De los veintiséis nombres que integraron la lista ${ }^{19}$, no todos a su regreso tuvieron significación y relevancia artística. Varios nombres se nos presentan, en esta perspectiva de tiempo, o como ilustres desconocidos, o como artistas de una muy menguada significación y trascendencia. El envío de estos pintores a Europa, en el contexto de esta cruda y excéntrica intervención estatal, redituó de igual forma algunos beneficios importantes para la cultura nacional. La crisis produjo consecuencias significativas en el escenario de la formación artística. En el año 1929, por Decreto Supremo, la Escuela de Bellas Artes, que transitoriamente había dependido del Ministerio de Instrucción Pública, pasó a depender de la Universidad de Chile. Se constituyó en Facultad, conjuntamente con la Escuela de Artes Aplicadas y el Conservatorio Nacional de Música ${ }^{20}$.

${ }^{17}$ Ricardo Richon Brunet (1886-1946) fue una especie de crítico oficial en Chile durante las primeras décadas del siglo XX. Autor del prólogo del catálogo de la Exposición del Centenario, su figura se cuenta dentro de las voces más influyentes de su época.

${ }^{18}$ Decreto Supremo, del 5 de marzo de 1929.

${ }^{19}$ La nómina de becados fue la siguiente: Jorge Madge Cortés, Julio Ortiz de Zárate, Camilo Mori Serrano, Isaías Cabezón Acevedo, Emilia Ladrón de Guevara Romero, Julio Vázquez Arriagada, Luis Vargas Rosas, Oscar Millán Valdovinos, Graciela Aranis Valdivia, Héctor Banderas Cañas, Gustavo Carrasco Délano, María Valencia Díaz, René Meza Campbell, Héctor Cáceres Osorio, Teresa Miranda, Laura Rodig Pizarro, Armando Lira, Laureano Ladrón de Guevara Romero, Abelardo Bustamante, Roberto Humeres Solar, Ignacio del Pedegral Corvalán, Inés Puyó León, Augusto Eguiluz, Marcial Lama Rojas y Rafael Alberto López.

${ }^{20}$ Se denominó Facultad de Ciencias y Artes Aplicadas hasta 1948, año en que pasó a llamarse Facultad de Bellas Artes. El Consejo Universitario aprobó, en 1936, el reglamento y los planes de 
El Salón de 1928 no había hecho otra cosa que profundizar el dilema que habían planteado ya los pintores del grupo Montparnasse cinco años antes. El cierre de la Escuela trajo otras consecuencias. Entre ellas, el impacto que genera en el medio cultural local la reinserción en el país de los "becados" por el general Ibáñez y la toma de posición de algunos de ellos en puestos influyentes de la Escuela y de la oficialidad cultural. Estos artistas portaban nuevas miradas estéticas, que comienzan a debilitar el modelo clásico hasta producir su reemplazo definitivo. Comienzan a preponderar ahora, en los espacios oficiales de enseñanza e incluso en la crítica, visiones estéticas vinculadas a posiciones más vanguardistas.

\section{TRES MAESTROS EMBLEMATICOS}

La Escuela de Bellas Artes fue, durante la primera mitad del siglo XX, un escenario marcado por conflictos y liderazgos. Hubo un fuerte debate entre conservadores y vanguardistas; un manifiesto intervencionismo del Gobierno, además de la presencia de algunos maestros emblemáticos.

\section{FERNANDO ALVAREZ DE SOTOMAYOR (1875-1960)}

El primero de ellos, que marca profundamente con su sello a muchos discípulos, fue el pintor español Fernando Alvarez de Sotomayor. Este artista fue contratado por el gobierno chileno en 1908. La revista Zig-Zag (1908) releva su llegada:

Se ha tenido en cuenta para este nombramiento, según se nos dice, la escasa cultura que adquieren los jóvenes artistas en los ramos de dibujo y composición, y la necesidad de que, junto a los aireados salones del nuevo edificio de Bellas Artes que proporcionara el Estado a los estudiantes de pintura, renueven los antiguos y rutinarios aires... por otros más vigorosos y sanos.

En la contratación de este pintor español se había comprometido directamente el Gobierno, que presidía don Manuel Montt. Con tal propósito se encomendó al cónsul general en España, Mathías Huelin, que contratara al pintor gallego. A su llegada a Chile la situación de la pintura presentaba matices diversos. En su casi centenaria vida como nación independiente el

estudio, permitiendo que los alumnos alcanzaran el grado académico de Licenciado en Bellas Artes.

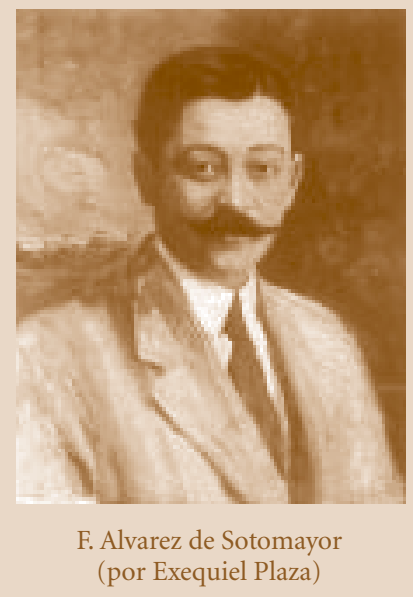




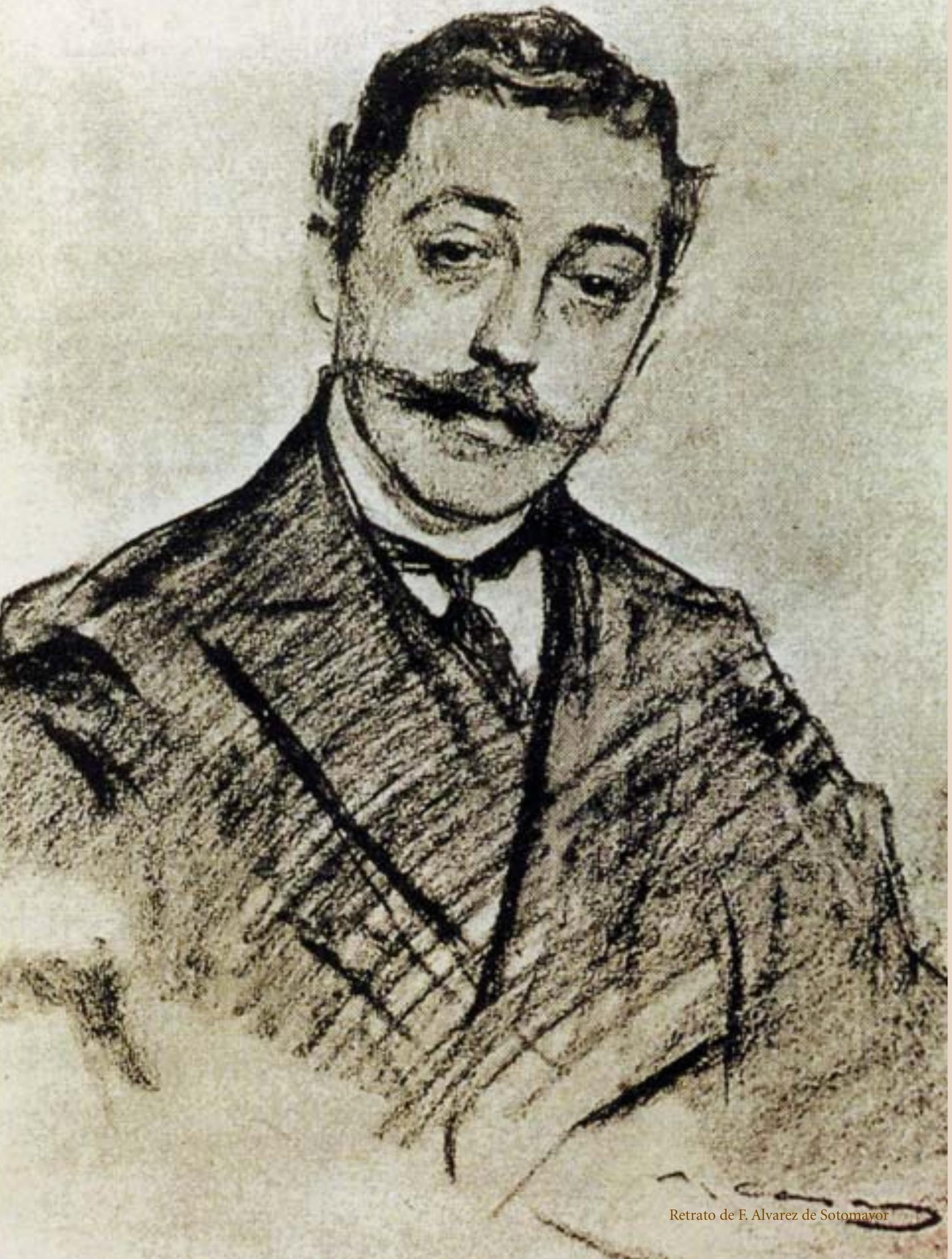


país no había logrado perfilar todavía su fisonomía cultural. Sin embargo, la preocupación de sus autoridades y las naturales inquietudes artísticas de una nación en donde, en este ámbito, estaba todo por hacerse, habían permitido un desarrollo no poco significativo de sus manifestaciones culturales. La llegada del pintor español a la Escuela fue un factor atenuante de los conflictos y rencillas que se habían generado al interior del plantel. Sotomayor -como se le conoce comúnmente- arribó a Santiago en agosto de 1908. En la estación ferroviaria lo esperaba el escultor Virginio Arias (1855-1941), quien por entonces oficiaba como director de la Escuela. En sus Memorias inéditas Alvarez de Sotomayor señalaba:

La corta conversación que tuve con él me dejó alarmado. Quise informarme de las rencillas existentes entre los artistas y deduje que mi ida a Chile había tenido por fin inmediato enfrentarme con las huestes que capitaneaba D. Pedro Lira, enemigo del citado D. Virginio y profesor de la Escuela (p. 116).

La verdad es que se habían definido dos bandos al interior del plantel. La división era de naturaleza ideológica y generacional. Los partidarios de cada uno de ellos eran no sólo los alumnos y profesores de la Escuela, sino toda la intelectualidad santiaguina de ese entonces. El poeta Manuel Magallanes Moure (citado por Montecino 1985: 104), escribió estos tajantes juicios en una publicación de la época:

El Director de la Escuela de Bellas Artes, cuyas glorias de artista soy el primero en reconocer, es un pésimo maestro. Los alumnos de la Escuela de Bellas Artes tienen toda la razón en el conflicto que se ha suscitado entre ellos y el Sr. Arias. En efecto, desde ocho o más años vienen sufriendo los estudiantes de arte un martirio comparable, solamente, al que deben experimentar los infelices súbditos de los sátrapas exóticos. Es que el Sr. Arias como toda persona incapaz de impresionar agradablemente y conquistar simpatías, pretende imponerse a sus alumnos por medio de la violencia, por medio del terror. Es un tirano el Sr. Arias.

El director tenía un temperamento irritable “... cuando no le gustaba el trabajo que algún alumno había comenzado a ejecutar, tomaba la tranca que se usaba para cerrar la puerta del taller y con ella deshacía a garrotazos las esculturas iniciadas por el alumno" (Montecino, 1985: 104). Al parecer, la llegada del pintor español produjo un cambio favorable en el beligerante mundo de la enseñanza artística nacional. El pintor Pedro Lira, la figura más emblemática en el escenario de la cultura local, no había mantenido con Arias relaciones cordiales. Un clima belicoso, que Arias había denunciado más de una vez ante el Consejo de Instrucción Pública, germinaba en la entidad. Según testimonios de la época, se hacía uso de anónimos, deman-
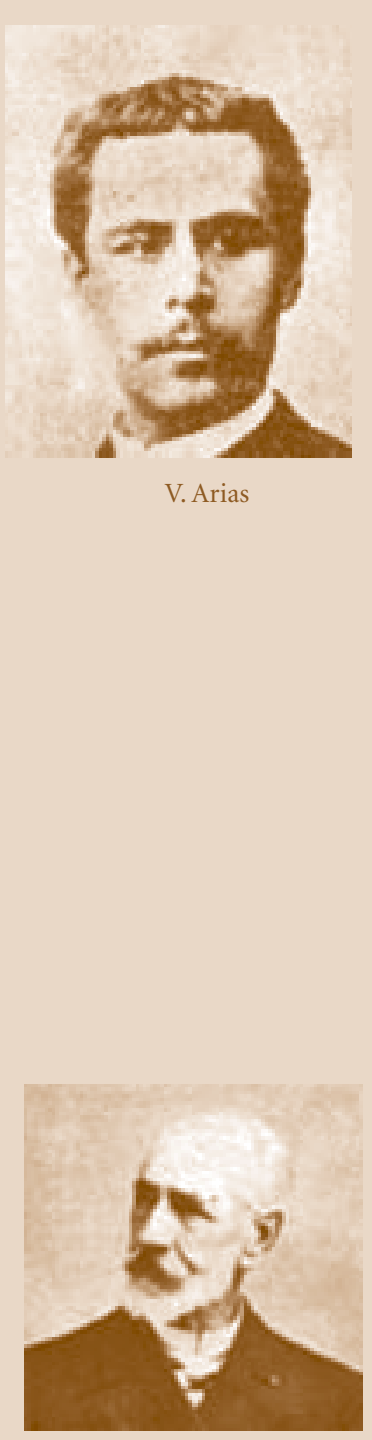

P. Lira 


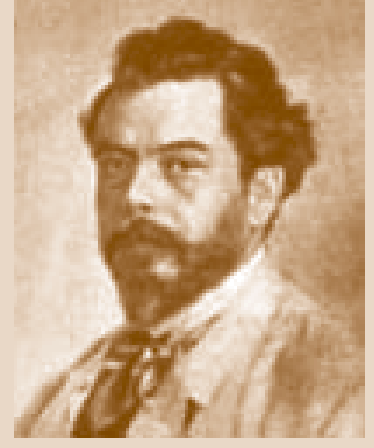

C. San Martín das judiciales, denuncias, huelgas, sabotajes a salones, etc., para lograr la salida del escultor. En esta dura batalla, la figura de Lira era el estandarte bajo el cual se agrupaban los inconformistas. Jorge Sanhueza (1956: 14) comentó al respecto:

Las ideas estéticas y pedagógicas de Lira eran, como lo dejó escrito claramente, contrarias a la intervención de las autoridades estatales y universitarias en la enseñanza. Pero como todos nuestros buenos artistas, al llegar la madurez creadora, se vio obligado a ceder al demonio de la pedagogía, a ese potente impulso de enseñar, que podía más que sus ideas. Y fue profesor por largos años, buen profesor, incómodo para Arias, pero valioso para el arte nacional.

Con Sotomayor en la Escuela cedió en parte este estrés emocional. El pintor gallego había reemplazado en la antigua cátedra de Dibujo Natural, Colorido y Composición ${ }^{21}$, al pintor Cosme San Martín ${ }^{22}$, quien había fallecido en 1906. El director Arias había realizado gestiones para transformar a esta asignatura en otra más actualizada y acorde a los intereses de los estudiantes.

Hacia 1908 la pintura chilena capitalizaba una corta pero interesante tradición. Había influido en ello el rol de la antigua Academia de Pintura, en donde se habían formado pintores por casi sesenta años. A comienzos de siglo la matrícula pasaba del millar de alumnos, contándose con un prestigiado cuerpo de profesores chilenos. "Por lo que se refiere al estado del arte en Chile, pronto comprendí que no correspondía a mis prejuicios y que era mucho más floreciente de lo que había imaginado" (Alvarez de Sotomayor, 1922). Además de la actividad generada desde la Escuela, estaba el Consejo de Bellas Artes, que se encargaba de organizar anualmente exposiciones oficiales y que llevaba la dirección del Museo, extendiendo su acción a todo cuanto fuese beneficioso al fomento de la cultura artística.

Pronto comprendí que gran parte del camino que creía había de recorrer estaba ya andado, y que mi labor había de dirigirse especialmente a encauzar el cariño y la atención de aquellos artistas hacia nuestra pintura, un poco olvidada y relegada a un segundo término por el deslumbramiento que producía entonces el arte francés (Alvarez de Sotomayor, 1922).

${ }^{21}$ Estos estudios se dividían de la siguiente forma: a) Dibujo de estatuas, copiando modelos clásicos, b) Dibujo y pintura tomados del modelo vivo, c) Composición de cuadros de variados géneros y distintas épocas. Día y hora de las clases: martes, miércoles, jueves, viernes y sábados, de 14 a 17 horas.

${ }^{22}$ Cosme San Martín (1849-1906) fue el primer director chileno de la Escuela de Bellas Artes. 
Por aquella época el interés por el arte era grande en un sector escogido de la sociedad culta y aunque el comercio de obras era bastante limitado, permitía de igual forma que un grupo reducido de artistas pudieran vivir de su trabajo creativo. Hacía ya muchos años que se celebraban en el país exposiciones de arte en forma periódica y en ellas se habían distinguido y ganado un nombre respetable varios pintores nacionales. Ello, además del importante respaldo que el Gobierno entregaba a estas actividades, propiciaba un panorama auspicioso para el desarrollo de estas actividades.

Era pues muy difícil mi situación -señala Sotomayor- pues no llegaba en plan de colonizador a un país de negros. Por el contrario, comprendía que era yo mismo el que tenía que ser juzgado y urgía que presentara mis títulos para disculpar mi posición en vista, además, de mi juventud. Aproveché la ocasión del primer certamen anual y presenté una docena de obras traídas de España y algunas ya hechas en Santiago. Momento peligroso pues, además, la pintura española estaba, por gracia del mercantilismo de ciertos viajantes de comercio, bastante desacreditada y el genio francés se había impuesto a través de los mismos artistas chilenos que habían estudiado siempre en París de espaldas a la Madre Patria (Alvarez de Sotomayor, sf.: 121).

Efectivamente, tal como se ha señalado, una de las características en la formación de los jóvenes pintores chilenos del siglo XIX y comienzos del XX dice relación con el anhelo de éstos de perfeccionar sus estudios en Francia. Hubo un programa de becas que permitió que muchos de ellos continuaran sus estudios, preferentemente, en París.

Hacia fines de 1910 Sotomayor obtuvo una licencia para viajar, junto a su familia, a España, en donde permanece por más de un año.

Cuando nos disponíamos a volver a Chile recibí un cablegrama en el que se me notificaba que había sido nombrado director de la Escuela de Bellas Artes de Santiago de Chile, lo que me llenó de legítimo orgullo, considerando lógicamente que mi anterior actuación había merecido la confianza del Gobierno chileno y de la opinión (Alvarez de Sotomayor, sf.: 125).

Efectivamente, estando aún en España, cuando se produjo la renuncia de Virginio Arias a la dirección de la Escuela, se nombró en el cargo al pintor peninsular. Este asumió a su regreso al país en 1912 y ejerció la dirección hasta marzo de 1913, fecha en que regresó definitivamente a su patria. En el corto tiempo que estuvo en la dirección, Sotomayor fue gestor de varias reformas en la enseñanza de la Escuela. Se creó un nuevo plan de estudios, más vasto y en cuya orientación se releva el sentido pedagógico de dichas materias. Este plan, que se sometió a consideración del Consejo de Instruc- 
ción Pública, contaba de doce secciones ${ }^{23}$. Tras el alejamiento del pintor español, asume la dirección de la Escuela el conocido escritor Luis Orrego Luco (1866-1948), quien había sido director de la revista Selecta, editada por la empresa Zig-Zag, entre 1909 y 1911. Posteriormente, entre 1916 y 1919 ejerció la dirección el escritor Joaquín Díaz Garcés (1877-1921).

Un día fuimos sorprendidos por una actitud extraña del Gobierno que desconcertó al alumnado de Bellas Artes: nos encontramos frente a otro Director. Se acababa de nombrar al escritor Díaz Garcés para imponer orden y apaciguar a los bohemios del Forestal. La gestión administrativa del nuevo funcionario se cumplió de acuerdo a las instrucciones recibidas, con espíritu de alcaide (Bontá, 1963).

El Gobierno me nombró Director para poner orden en esa olla de grillos de la Academia de Bellas Artes (Díaz Garcés, citado por Bontá, 1963).

A este respecto Ricardo Bindis (2006: 234) señala:

Los estudiantes de arte discutían sobre una reforma de los planes de estudio y el Parque Forestal bullía con nuevas maneras de enfocar el futuro. Con proclamas, discursos encendidos y antorchas, cayó el escritor Díaz Garcés, director de la Escuela de Bellas Artes.

A Díaz Garcés le sucede el escultor Carlos Lagarrigue (1858-1928), quien contó con el apoyo y la estimación de los estudiantes ${ }^{24}$. Habiendo éste jubilado en 1927, fue nombrado director de la Escuela y el Museo de Bellas Artes, el pintor y músico Carlos Isamitt (1887-1975) ${ }^{25}$. Este artista consigue

\footnotetext{
${ }^{23}$ Primera sección, "Curso de dibujo", a cargo de José Mercedes Ortega; segunda, "Pintura y dibujo superior" (Pedro Lira); tercera "Dibujo natural, colorido y composición” (Fernando Alvarez de Sotomayor); cuarta "Escultura estatuaria” (Virginio Arias); quinta "Grabado en madera” (León Bazin); sexta "Arquitectura" (José Forteza); séptima "Modelo y dibujo ornamental” (Simón González); octava "Desbaste y práctica del mármol y de la piedra” (Baldomero Cabré); novena "Clases orales y gráfica” (José Forteza); décima “Anatomía de las formas” (David Benavente); undécima "Historia universal y mitología" (Enrique Nercasseau); duodécima "Estética e historia del arte" (Alejandro Fuenzalida Grandón).

24 "Al entregar la dirección de la Academia al escultor nacional, maestro Carlos Lagarrigue, en 1919, hubo un sentimiento de alivio en los artistas, ya que la solución representaba un retorno a la trascendencia e importancia que tienen los valores técnicos. Lagarrigue posee las cualidades del verdadero maestro, de espíritu laico, abierto, que sabe escuchar, le interesa el pensamiento de la juventud y, además, conoce su oficio de escultor. Con él todo cambia, nace una nueva tónica basada en el ejemplo y en la comprensión, en la amistad entre profesores y alumnos” (Bontá, 1963: 94).

${ }^{25}$ Pocos días después de este nombramiento, un extraño decreto promulgado por el Gobierno obligaba a renunciar a la administración pública a toda persona mayor de sesenta años, medida que afecta entre otros a Virginio Arias, Carlos Lagarrigue, Richon Brunet y Juan Francisco González, quienes tuvieron que dejar sus cátedras en la Academia. Lagarrigue no resiste el inesperado golpe y muere a los pocos días, Juan Francisco González se limita a exclamar... "me echaron por viejo”.
} 
generar una atmósfera positiva de trabajo, ensanchando el espacio de las artes visuales con la creación de la Escuela de Artes Aplicadas. Isamitt estuvo en el cargo hasta 1928.

Una vez reabierta la Escuela en 1931, luego del cierre decretado por el Gobierno, asume la dirección el pintor Julio Fossa Calderón (1874-1946), ejerciendo el cargo hasta 1932. Por esta época la Escuela pasa a depender de la Universidad de Chile.

Volviendo la mirada a la gestión de Sotomayor, lo más significativo de este corto segundo periodo (1912-13) en tierras chilenas dice relación con su labor en la dirección de la Escuela, en donde, además de realizar algunas reformas a los estudios, fue adquiriendo fisonomía estética un conjunto de pintores formados bajo su magisterio, los que serán conocidos posteriormente como Generación de 1913, o Generación del Centenario ${ }^{26}$, o "Heroica Capitanía de Pintores”, como la llamó Pablo Neruda. Este grupo de artistas, más allá de su vínculo de condiscípulos, expresaron una fuerte afinidad espiritual que dio coherencia y singularidad a su creación como grupo. Algunos de estos pintores procedían de hogares acomodados, de clase media, pero también muchos, quizá la mayoría, venían de modestas familias, enclavadas en los barrios más pobres de la capital. Su pintura, en consecuencia, se hizo parte de esa condición social y cultural. Los temas de sus obras retratan al Chile popular, campesino, además de los conflictos sociales que comienzan a impactar con fuerza en el país en las primeras décadas del siglo XX.

Alvarez de Sotomayor, conocido en España por sus retratos y la gestión realizada en la dirección del Museo del Prado, hace también una contribución relevante a la pintura regionalista ${ }^{27}$. Esta veta es posible que haya orientado la mirada de sus discípulos hacia una pintura de corte costumbrista. De este modo, el repertorio iconográfico de estos artistas, al igual que algunos aspectos técnicos relacionados con el dibujo y el color, sufre modificaciones relevantes. Aparecen algunos temas sociales, tales como velorios de angelitos, retratos de personajes populares, paisajes costumbristas, escenas de borrachos, entre otros. Capítulo aparte merece su esfuerzo por valorar el

${ }^{26}$ Esta denominación se debe a una exposición que realizaron algunos discípulos de Fernando Alvarez de Sotomayor en el año 1913, en los salones del diario El M ercurio de Santiago. Expusieron en la oportunidad Pedro Luna, Ulises Vázquez, José Prida, Guillermo Maira y Abelardo "Paschín" Bustamante. A este grupo se deben sumar los nombres de Agustín Abarca, Ezequiel Plaza, Arturo Gordon, los hermanos Alfredo, Alberto y Enrique Lobos Aránguiz, Enrique Bertrix, Enrique Moya, entre otros.

${ }^{27}$ Fernando Alvarez de Sotomayor tiene una obra prolífica en la pintura española del siglo $\mathrm{XX}$. En términos generales ella se divide entre los retratos de alta sociedad, dentro de los cuales se pueden contar los del Rey Alfonso XIII, y su pintura regionalista. Es considerado como uno de los artistas que mejor recoge las costumbres y tradiciones de su tierra natal: Galicia. Conocidos son sus pescadores, labriegos, comidas de bodas y foliadas.

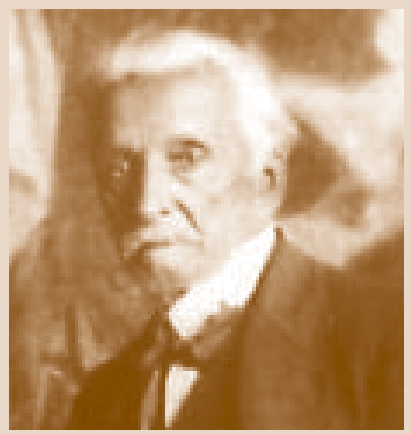

J. F. González 
arte peninsular. La pintura chilena, que se había caracterizado durante gran parte del siglo XIX y comienzos del XX por situarse bajo modelos franceses, comienza a mirar con interés a los artistas hispanos. Sería desproporcionado suponer una reorientación ideológica demasiado profunda del arte nacional, sin embargo, algunos de estos pintores, entre ellos Arturo Gordon (1883-1944), suscriben modelos "goyescos". Otros, como Benito Rebolledo Correa (1880-1964), ven en el luminismo levantino y en la obra de Joaquín Sorolla un referente inspirador. La idea de hispanidad tuvo más fuerza en el discurso oficial -circunstancia propiciada sobre todo por la celebración del Primer Centenario de la Independencia Nacional-y en la retórica obsecuente de algunos críticos e historiadores de la época, que en la producción artística nacional. El "paréntesis de hispanidad" que representan estos pintores dice relación más bien con una aspiración generada en parte por la amable figura de este pintor español y también por la celebración de nuestra primera conmemoración secular. La exaltación que hace Domingo Gómez Ro$\mathrm{jas}^{28}$, con motivo del viaje a la península del pintor Alfredo Lobos Aránguiz, es testimonio elocuente de este anhelo de hispanidad.

\section{JUAN FRANCISCO GONZALEZ (1853-1933) ${ }^{29}$}

La huella que dejara en sus discípulos se ha prolongado a través del recuerdo vigente de sus enseñanzas y reflexiones y así la luz de su espíritu sigue iluminando aún a generaciones posteriores (Lobo Parga, 1981).

Juan Francisco González Escobar fue otro de los artistas que marcó a muchos pintores con su gestión como profesor ${ }^{30}$. Realizó una labor pedagógica

28 "Alfredo Lobos fue el primero que realizó el sueño de todos: ir a la España de nuestros amores. Nada mejor para un pintor chileno deseoso de estudiar, orientarse y definirse, que ir para ello a España, que es hoy por hoy, la mejor escuela de pintores. Muchas ventajas tiene España al respecto, en comparación con los demás países y más aún para nosotros los indoamericanos. Un lenguaje que es propio, la afinidad de valores comunes, diversas fuerzas que hablan con la voz de los siglos y con elocuencia histórica de un vínculo espiritual, imborrables rasgos etnográficos y una noble blasonada tradición nos determinan a pensar de este modo" (Gómez, 1918).

${ }^{29}$ Juan Francisco González, además de pintor, cultivó una importante veta literaria. Artículos suyos aparecieron en distintos periódicos de su tiempo, Pluma y lápiz, La lira chilena, Instantáneas deluz y sombra, entre otros. En el primer número de la revista de Los Diez, aparecido en 1916, hay un cuento suyo. "El Cachespeare", narración costumbrista que describe aledaños de la Iglesia Matriz, barrios de la bohemia y el hampa de Valparaíso. Otros escritos: "Un recuerdo de antaño", "Las hojas de otoño", "La pátina" y "Cartas a María Tupper".

30 "Estos seres son los maestros. Maestro es el que nos revela nuestra primitiva sensibilidad, el que nos interna en nuestro propio conocimiento. Maestro es el que nos arranca del letargo de confusión y suficiencia de la vida y nos entrega a la esperanza ardiente y al ansia de realizaciones superiores. Maestro es quien nos extrae de nosotros mismos y nos arroja más allá de nuestras propias fuerzas. Maestro es quien libera en nosotros el espíritu y hace que él nos posea y nos conduzca" (Prado, 1948: 28). 


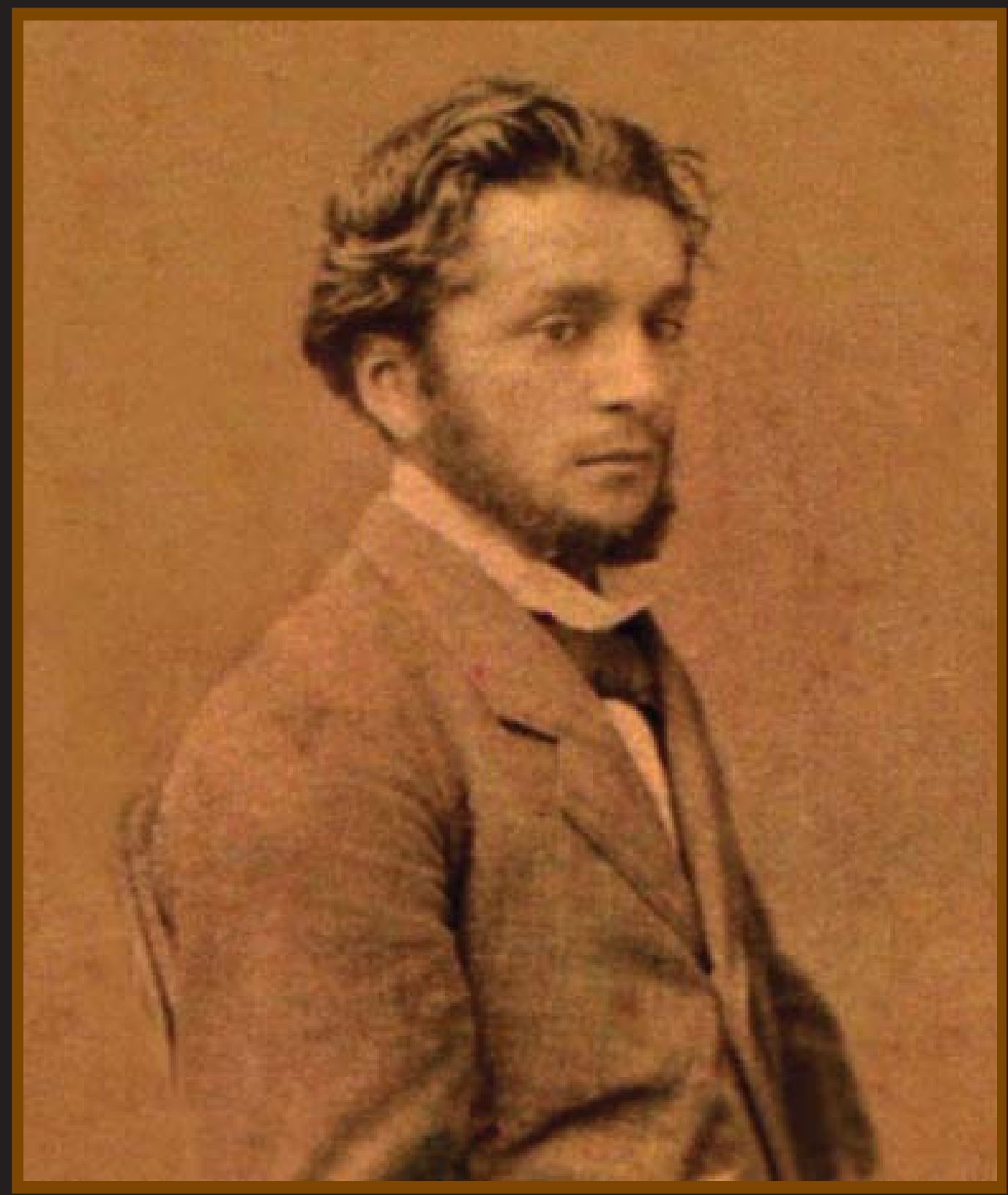

J. F. González 
extensa que abarcó desde clases a alumnos libres hasta docencia universitaria. En 1884 se establece en Valparaíso, siendo nombrado ese mismo año como profesor de Dibujo del Liceo de Hombres, cuyo rector por esa época era el filólogo y humanista Eduardo de la Barra. En 1895 renuncia a su puesto de profesor, en cuyo curso estuvo por diez años, y en donde habían figurado como alumnos algunos pintores que luego destacaron, tales como Pedro Reszka Moreau (1872-1960) y Julio Fossa Calderón (1885-1946). En 1887 González emprende el primero de los tres viajes que realizó a Europa. Con tal motivo el ministro de Instrucción Pública le encomienda la misión ad honorem de estudiar allí la organización de museos y la enseñanza del dibujo. A su regreso, en 1889, presenta al Ministerio de Instrucción Pública un texto de dibujo moderno para su aprobación como material didáctico para la enseñanza de las artes plásticas. En él sistematizó sus estudios y experiencias en el viejo continente. En 1906, después de su tercer viaje a Europa, dicta en el Salón de Honor de la Universidad de Chile la conferencia "La enseñanza del dibujo", la que es publicada, ese año, en los Anales de la Universidad. En 1910 es nombrado profesor de croquis y dibujo del natural en la Escuela de Bellas Artes. "Con ese nombramiento, se pensó dar impulso renovador a la enseñanza artística de ese plantel, la cual estaba invadida por un espíritu academizante ancestral"31. Efectivamente, cuando Virginio Arias abandona la dirección de la Escuela de Bellas Artes, el artista se incorpora como profesor en ese plantel ${ }^{32}$, a instancias del nuevo director Alvarez de Sotomayor. Desde esta cátedra promueve sus convicciones estéticas, que diferían respecto del tradicional perfil de enseñanza de la entidad. A decir de Luis Vargas Rosas (1953), la anodina y fría clase de dibujo la transforma en un "viviente taller de trabajo". La Escuela en ese momento era un lugar de enconos y desavenencias, "un pozo de pasiones encontradas", como ha señalado el propio pintor. González polemizó en forma violenta con el director Díaz Garcés. Como se ha señalado, el escritor fue nombrado como director con facultades omnímodas, para reestablecer el orden en el plantel. Una de sus órdenes fue:

Todo alumno que tenga peticiones o reclamos a la Universidad o al Ministerio pasando por la Dirección se le considerará insubordinado i se les suspenderá temporalmente. El que no acepte este temperamento puede buscar otra parte en donde estudiar su arte (Díaz, 2004: 169).

${ }^{31}$ Catálogo "González hoy", sala BHC, marzo-abril 1981.

32 "Alvarez de Sotomayor, en 1910, me hizo nombrar profesor. Dijo que yo iba a ser una inyección para la Escuela”. Juan Francisco González, citado por Zegers (1981: 157). 
Al disentir de estos procedimientos González se vio obligado a alejarse del plantel. Su renuncia en 1918 dio origen a serios incidentes, con ingreso de la fuerza pública a la Escuela. La Federación de Alumnos de Chile solidarizó con el maestro, acordando enviar una carta al ministro de Instrucción Pública en que solicitan la renuncia del director Díaz Garcés, además del reintegro del pintor a la clase de dibujo. El Ministerio dio su respuesta según un comunicado de prensa dirigido a Díaz Garcés, en que se informa acerca del rechazo de la renuncia de González y de la creación de una subdirección que mantenía en su cargo al cuestionado director. Frente a ello la FECH acordó no cejar en su empeño de sacar de igual forma al cuestionado director.

Juan Francisco González, a decir de Isabel Cruz (1984: 263), fue un maestro de "figura patriarcal", que influyó fuertemente con su personalidad en un número importante de discípulos. "Yo tenía ojos, pero él me enseñó a ver", señaló Pedro Prado (1947). El grupo Montparnasse vio en él un referente orientador. De hecho, fue invitado por estos artistas al Salón de 1925, que ellos habían organizado. A los 72 años González expone junto a estos jóvenes en una muestra en donde también exhibía Vicente Huidobro sus caligramas.

González desarrolló un tipo de enseñanza muy libre, en donde los alumnos eran los verdaderos protagonistas del proceso de aprendizaje. En sus clases de dibujo hacía trabajar incansablemente a sus discípulos en varias sesiones, acortando cada vez el tiempo dedicado a dibujar el modelo hasta que el ojo, habiendo retenido la imagen, fuera capaz de dibujarlo sin su presencia $^{33}$. En 1918 González funda la Sociedad de Bellas Artes, para contrarrestar, en beneficio de la innovación artística, las ideas conservadoras propugnadas por la Escuela y, sobre todo, por la Comisión de Bellas Artes. Este artista, podríamos decir, fue el primero que objetó en Chile y de manera decidida el paradigma clásico. Por esta razón su pintura no gozó, en su momento, de la estimación de los sectores sociales influyentes ni del exiguo poder comprador local. La crítica de arte tampoco fue benévola con el maestro; Ricardo Richon Brunet, crítico y pintor académico, lo consideraba como

\footnotetext{
33 "El maestro exigía que sus discípulos no se contentaran con dibujar el modelo desde una posición fija, sino que lo recorrieran y lo captaran en todos sus ángulos. Solicitaba también a sus alumnos que adoptaran una actitud de soltura, pero, a la vez, de extrema atención en relación al trabajo que estaban realizando, donde no sólo la mano sino todo el cuerpo participaba en la acción que se ejecutaba. En contraste con el dibujo académico, el maestro no prestaba atención al 'dibujo acabado', rechazando categóricamente el detallismo fotográfico que habitualmente servía para evitar los desbordes del color; según aquella técnica, el color se aplicaba una vez corregidas, retocadas y muy bien definidas las líneas. Para el maestro, ni la línea ni el color estaban destinados a cumplir esos fines, sino que ambos eran una síntesis de la realidad observada" (Ivelic y Galaz, 1981: 134).
} 
extravagante y demasiado vanguardista. Aun así, su magisterio aglutinó a muchos artistas, quienes le vieron como un líder artístico y un ejemplo a seguir $^{34}$.

Por primera vez en la historia artística de nuestro pequeño Chile, surgió con él la figura de un maestro; sus precursores en la pintura chilena hacían clases, enseñaban, corregían; don Juan Francisco vitalizaba. Luchó con un fuego que antes no se quemaba en las contiendas de arte, excluía, fulminaba. Y ese ritmo de lucha, propio de visionarios, hizo vibrar electrizado al grupo juvenil que antes de él desperezaba en las salas de la Escuela de Bellas Artes. Toda acción fecunda necesita el estímulo de una ceguera apasionada y al negarse a las transacciones y al embestir contra el arte académico del siglo XIX, con el encono que se embiste al adversario desleal, hizo sentir a los que le seguían -que fue toda la juventudque el arte era un sacerdocio, una función altísima (Alfonso Bulnes, citado por Zegers, 1981: 158).

Waldo Vila Silva (1894-1979), pintor e historiador, recuerda al maestro:

Curioso y gran maestro era nuestro Juan Francisco González pienso ahora. Con aquella, su enseñanza, nos liberaba del academismo muerto y de la fría petulancia de los "lame-telas", ... nadie podía hablar de nuestros años y de aquella generación (de 1913) sin detenerse en la sombra de aquel árbol añoso de la pintura chilena, del cual todos nosotros, grandes y pequeños, somos sus ramas (Alfonso Bulnes, citado por Zegers, 1981: 159-160).

Juan Francisco González fue el principal gestor en el proceso de innovación artística en nuestro país. Su obra, especialmente aquella relacionada con su etapa de madurez, rompe con los esquemas académicos de su tiempo. Su presencia pictórica muestra, además, una veta profunda en relación con la teoría y la crítica de arte. Dictó conferencias, escribió en la prensa con el pseudónimo de "Araucano" y se mezcló en grandes polémicas con los

\footnotetext{
34 "Fui profesor de todas esa chicas con tanto talento: Enriqueta Petit y Marta Villanueva, extraordinaria; de Inés Puyó León, que tiene el porvenir entre las manos; también fui profesor de María Tupper de Aguirre; de María Valencia, gran talento; de Anita Cortez, mi mejor alumna. Entre los hombres también tuve algunos distinguidos: el inquieto talento de Mori; ese muchacho Del Pedregal, que va a llegar lejos; Vargas Rosas, lleno de condiciones; el arquitecto Juan Martínez, que triunfó en el concurso para el pabellón de Sevilla; Laureano Guevara, mi mejor e inolvidable alumno. Han sido tantos. ¿Cómo recordarlos así de un solo golpe?” (Zegers, 1981: 158).

También se cuentan dentro de sus discípulos a Alfredo Helsby, Pablo Burchard, algunos pintores de la Generación del Trece, entre ellos Abelardo Bustamante y Pedro Luna. Se le considera también como orientador ideológico del grupo Montparnasse y la Generación de 1928.
} 
defensores de la pintura académica ${ }^{35}$. Encendidas disputas tuvo con Pedro Lira, quien en carta dirigida a Ramón Subercaseaux, le manifiesta que en el salón de 1894 González había expuesto

una verdadera avalancha de impresiones de singular atrevimiento, y que si bien es incapaz de hacer un cuadro por cuanto en él la impresión, aunque profunda y ardiente, es demasiado fugitiva y su educación de artista es incompleta (él va a fusilarme por estas palabras), en cambio hace improvisaciones como no las hace nadie, y que los artistas preferimos a muchos de sus cuadros acabados.

Alvarez de Sotomayor tampoco entendió la propuesta plástica de nuestro pintor. En sus M emorias inéditas, en poder de la familia, el artista español comenta:

... pintor bohemio de grandes cualidades de colorista pero desordenado hasta en su manera de vivir y sus obras de arte son chispazos de luz sin resolver nada en definitiva.

González fue un pintor antiacadémico que rechazaba el realismo artesanal y el parecido fotográfico. Incursionó, incluso, en el cine: en 1925, bajo la dirección de Jorge Délano, actúa en el filme "Luz y sombra". La gran premisa y fundamento de González fue creer que el secreto de la belleza consiste en lograr el máximo de efecto, con el mínimo de detalles. Es decir, la simplicidad formal, sustento de una visión impresionista a la que adhirió, más que en sus postulados técnicos, al espíritu renovador que representan estos artistas.

A principios del siglo XX nuestro artista se vincula con la Colonia Tolstoyana, grupo de intelectuales que preconizaba el contacto directo con la naturaleza, el trabajo de la tierra y la comunidad de bienes ${ }^{36}$. La Colonia debe ser entendida como una alianza espontánea de poetas, músicos, pinto-

\footnotetext{
${ }^{35}$ Una de las polémicas más duras fue la que se generó a raíz de la crónica titulada "Obras de arte”, aparecida en el periódico La Unión, de Valparaíso, el 24 de abril de 1894. En la crónica, el articulista alaba un retrato realizado por el pintor W.H. Walton, en donde se señala: "En actitud natural y tranquila, con una expresión llena de vida, el señor Salas tiene en la mano un cigarrillo, en que uno cree que puede encender su propio cigarrillo...". En la réplica, publicada en El Heraldo, González señala lo siguiente: "Y no menos ancho de tragaderas que el público deben ser los susodichos cronistas, para dejarse embaucar por estos pordioseros de alabanzas, que para lograr reputación asaltan las imprentas sin perdonar ocasión. Cada vez que han hecho la gracia de iluminar en tela la fotografía agrandada con la cámara solar, con cuya superchería y con la desvergüenza en que les ayudan los cronistas, la pegan al público pasándole por arte lo que no es sino la adulteración industrial de la fotografía y la falsificación más injuriosa que se puede hacer del arte de Velázquez y Rafael".

${ }^{36}$ En una propiedad que facilitó Manuel Magallanes Moure, en San Bernardo, tuvo lugar la vida de la Colonia, encabezada por Augusto D’Halmar e integrada por Fernando Santiván, el escultor español Canut de Bon y los pintores Julio Ortiz de Zárate, Benito Rebolledo y Pablo Burchard.
}

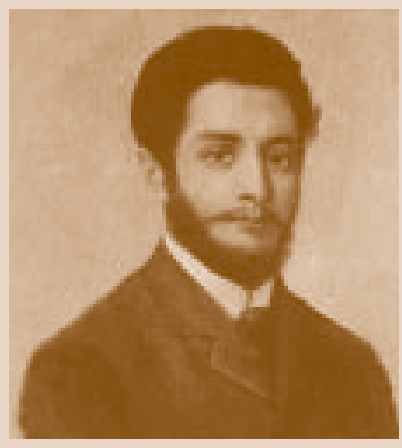

J. F. González 
res y arquitectos. No se trata ni de una secta, ni una institución, ni una sociedad. Carecen de disposiciones normativas y no pretenden otra cosa que cultivar el arte con una libertad natural. No establecieron un estilo, no dieron normas y pautas. Cada cual cultivó su arte conforme su propio criterio y visión.

Juan Francisco González participó activamente también en la formación del grupo Los Diez ${ }^{37}$, conjunto de intelectuales, liderados por Pedro Prado, que se aglutinan a partir de convicciones vanguardistas. No se oficializa entre ellos unión alguna, aun cuando manifiestan una posición de cierta coincidencia. De este ambiente de innovación, que todavía se manifiesta desde posiciones marginales, participan muchos otros artistas e intelectuales, quienes cuestionan el poder absolutista del modelo clásico, promoviendo una nueva sensibilidad estética. Ernesto A. Guzmán (cit. por Ibáñez Santa María, 1976), en una polémica con los críticos de su época, reafirma esa postura:

Somos hombres de nuestro tiempo; vivimos con las ideas y los sentimientos de la época; nos movemos en el ambiente actual de una renovación de tendencias artísticas; no podemos abandonar el contacto con este momento de la vida, en que nos ha tocado actuar.

Pedro Prado definía el hacer artístico como "un proceso de liberación, de pureza y de alegría desbordante”.

El Centenario había sido un motivo para revisar nuestros procesos identitarios, pero también lo fue para propiciar una mirada crítica al pasado y para cuestionar las oxidadas fórmulas dieciochescas. La inquietud de la modernidad ya se comenzaba a instalar en el corazón de nuestra intelectualidad. González tuvo mucho que ver en ello.

\section{PABLO BURCHARD (1873-1964)}

"La pintura tiene la intensidad de la mirada y Burchard miró y pintando inició un largo diálogo que lo llevó a la verdad”, señaló Adolfo Couve (1966).

Sus maestros iniciales fueron Cosme San Martín, luego Pedro Lira y Fernando Alvarez de Sotomayor, artistas académicos de los cuales se aleja logrando dar forma a una obra más personal. "Ninguna influencia apreciable dejaron en mi espíritu ambos maestros. Aprendí de ellos, es cierto, la práctica

${ }^{37}$ A pesar de su nombre, los integrantes de este grupo no fueron necesariamente diez. El núcleo fundamental está constituido por Pedro Prado, Manuel Magallanes Moure, Juan Francisco González, Armando Donoso, el arquitecto Julio Beltrand Vidal, quien fuera reemplazado en la hermandad por Eduardo Barrios, Alberto García Guerrero, Alberto Ried, Acario Cotapos, Ernesto Guzmán, Augusto D’Halmar y Alfonso Leng. 


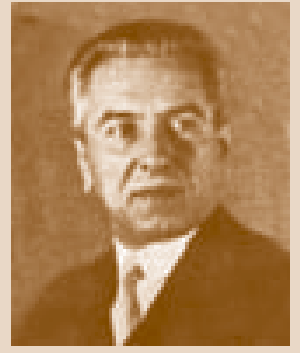

J. Fossa Calderón del oficio. Pero su visión pictórica nunca me satisfizo" (Burchard, cit. por Humeres, 1955: 9). Burchard es estrictamente contemporáneo de los pintores de 1913, sin embargo, su obra dista en inspiración y en posición estética de la obra de estos artistas. Su primera experiencia docente data de 1903, cuando, en una escuela secundaria de Talca, se desempeña como profesor de dibujo. Más tarde, continuó ejerciendo el cargo de profesor de dibujo en el Liceo de Niñas $N^{\circ} 6$ de Santiago y desde 1932 en adelante en la Escuela de Bellas Artes de la Universidad de Chile, en donde reemplaza en la dirección al depuesto Julio Fossa Calderón, quien renunciara a consecuencia de la crisis y una serie de conflictos recientemente vividos en la Escuela. Burchard ejerce la dirección de la entidad sólo hasta 1935, alejándose del cargo para dedicarse de lleno a la creación y mantener su cátedra de pintura que conservó hasta $1959^{38}$. El magisterio de este artista marcó toda una época. Su discípulo Armando Lira (1955) destaca su labor docente:

Es un gran profesor de pintura; pero sus enseñanzas son de índole filosófica... Sus lecciones son sugerencias sobre los problemas de la plástica frente a la naturaleza. Enseña a ver e interpretar los elementos objetivos en forma pictórica: el juego de las luces, los contrastes del colorido, el arabesco del dibujo, la organización del cuadro. Pero, por sobre todas las cosas, este maestro, mediante su aguda observación, hace sentir la poesía serena del paisaje.

En lo que respecta a su creación artística, Burchard es un agudo observador de la naturaleza. Su obra está cruzada por dos elementos centrales: la naturaleza y la búsqueda de la esencialidad plástica. A decir de Enrique Lihn (1956): "El problema que Pablo Burchard se plantea en materia de composición es el de equilibrar el mínimo de elementos en el máximo de espacio". No hay en su obra afanes literarios ni extravagancias conceptuales, tampoco testificaciones documentales, posiciones ideológicas o discursividad narrativa; hay simplemente una propuesta estética. El artista se va despojando de aquellos elementos innecesarios a los objetivos de una racionalidad básicamente pictórica. Su lenguaje "se hace mínimo; con él puede decir lo máximo, allí radica su valor de pintor fundamental" (González, 1996: 20). Su obra es un elogio a los temas sencillos, a lo cotidiano.

Mire compañero [señala el pintor], para qué emprender recetas y teorías, para qué complicarse la vida con grandes problemas, cuando ahí -mire usted- tiene abierto el gran libro de la naturaleza para reflexionar, sentir

\footnotetext{
${ }^{38}$ Hasta 1959 Burchard se desempeña como profesor en la Escuela de Bellas Artes, dictando la cátedra de pintura en forma paralela a la de los pintores Jorge Caballero y Augusto Eguiluz.
} 
y aprender. ¿Con qué fin tantas complicaciones cerebrales, tanta metafísica y dogmas estéticos? (Lira, 1955: 14).

El centro de su pedagogía fue el alumno. A través de los distintos procedimientos didácticos, realizados directamente por el profesor, procuraba siempre la formación de la personalidad artística del discípulo. Su objetivo fue que el alumno resolviera por sí mismo los problemas en la elaboración de sus cuadros para que, de esa forma, fuera articulando su lenguaje expresivo. Según Armando Lira (1955) el maestro enseñaba a distinguir lo esencial de lo accesorio en una obra, con el propósito de que el alumno “... sepa desdeñar en el cuadro todo elemento objetivo que no convenga a la armonía y claridad artística que debe tener una buena pintura". Sus discípulos valoraron a Burchard como un hombre sabio, de juicio reposado, de elevadas condiciones humanas. Su virtud más relevante fue su capacidad de infundir fe y entusiasmo en sus alumnos. La mejor pedagogía, a fin de cuentas, es siempre eso; lograr transmitir el cariño y la pasión por el oficio que se enseña.

En 1951 realiza su único viaje a Europa, un viaje tardío realizado a los 77 años de edad. Esta circunstancia libera al artista de un teórico pecado de filiación. Su obra y por ende su magisterio tuvo escasa supeditación respecto de las teorías y los modelos foráneos. Como es sabido, casi todos los artistas nacionales contemporáneos habían delineado su lenguaje estético y por ende sus concepciones artísticas en el contacto con las academias y los escenarios artísticos europeos. Aun cuando siempre es posible y tentador parangonar la obra de un pintor, en el caso de Burchard debemos admitir la posibilidad de una concepción estética más bien particular. Por esta razón su obra es difícil de encasillar en corrientes determinadas. "Al margen del clasicismo o la vanguardia creó una obra personal en que la soledad marcó su íntima relación con la naturaleza" (González, 1996: 10).

Varios artistas posteriores suscriben sus postulados estéticos, entre ellos podemos mencionar a Augusto Barcia, José Balmes, Gracia Barrios y Adolfo Couve, entre otros.

Alvarez de Sotomayor, Juan Francisco González y Pablo Burchard son tres maestros de figura patriarcal que marcaron con su presencia el escenario de la pintura chilena. Aun cuando sus repertorios estéticos no fueron coincidentes, resaltan por la solidez de sus principios artísticos, por la pasión con que abrazaron su oficio, por la calidad y fecundidad de su obra artística y por el magnetismo de su magisterio. Se trata de personalidades aglutinantes, que ejercieron un fuerte liderazgo en los jóvenes artistas nacionales. Los tres fueron profesores en la Escuela de Bellas Artes; dos de ellos, Alvarez de Sotomayor y Burchard, también llegaron a ocupar la dirección del plantel, aun cuando por un breve periodo. Tres figuras que marcan con su presencia la escena pictórica nacional. 


\section{REFERENCIAS}

Alvarez de Sotomayor, Fernando. 1922. "Nuestras relaciones artísticas con América”. Discurso leído en el acto de su recepción pública a la Real Academia de Bellas Artes de San Fernando, el 22 de marzo. Madrid: Academia Mateu, Artes Gráficas.

. s.f. "Recuerdo de un viejo pintor". Documento inédito con las memorias del artista.

Bindis, Ricardo. 2006. Pintura chilena: D oscientosaños. Santiago de Chile: Origo Ediciones.

Bontá, Marco A. 1963. "Medio siglo de vida artística chilena”. Atenea N 402.

Couve, Adolfo. 1966. Burchard. Santiago de Chile: Editorial Universitaria S.A.

Cruz de Amenábar, Isabel. 1984. Arte, historia de la pintura y la escultura en Chile, desdela Colonia al siglo XX. Santiago de Chile: Editorial Antártica.

Díaz, Wenceslao. 2004. Juan Francisco González: Cartasy otros documentos desu época. Santiago de Chile: RIL Editores.

Gómez Rojas, Domingo. 1918. Pacífico Magazine, junio.

González, Francisco. 1996. "Pablo Burchard: Un pintor fundamental”. Catálogo de exposición. Santiago de Chile: Corporación Cultural de Las Condes. Septiembre.

Humeres Solar, Carlos. 1955. Pablo Burchard. Santiago de Chile: Ediciones del Instituto de Extensión de Artes Plásticas, Universidad de Chile.

Ibáñez Santa María, Adolfo. 1976. "Reseña histórica”. En: Los Diez en el arte chileno del siglo XX. Santiago de Chile: Edit. Universitaria.

Ivelic, Milan y Gaspar Galaz. 1981. La pintura en Chile: Desde la Colonia hasta 1981. Valparaíso, Chile: Ediciones Universidad Católica de Valparaíso.

Letelier, Jorge. 1936. “Salón Oficial de Artes Plásticas”, Revista deArte, N 12.

Lira, Armando. 1955. Pablo Burchard. Santiago de Chile: Ediciones Instituto de Extensión de Artes Plásticas, Universidad de Chile.

Lihn, Enrique. 1956. "Actualidad de Pablo Burchard: Más de medio siglo en el oficio artístico”. Revista de Arte $\mathrm{N}^{\circ} 4$.

Lizama Améstica, Patricio. 1992. Jean Emar, escritos dearte(1923-1925). Santiago de Chile: Dirección de Bibliotecas Archivos y Museos.

Lobo Parga, Luis. 1981. "González hoy" (Catálogo). Sala BHC, marzo-abril.

Montecino, Sergio. 1985. Entre músicos y pintores. Santiago de Chile: Editorial Amadeus.

Parragón, Edgar. 2005. Armando Lira. Chillán, Chile: Impresora La Discusión S.A.

Prado, Pedro. 1947. "Juan Francisco González". Arte y Cultura N 5.

. 1948. "Juan Francisco González (fragmento de discurso)”. En Viaje, No 171: 28.

Revista de Arte. Universidad de Chile, Instituto de Extensión de Artes Plásticas, $\mathrm{N}^{\circ} 3$, abril-mayo. 1956.

Revista de Arte. Universidad de Chile, Instituto de Extensión de Artes Plásticas $\mathrm{N}^{\circ} 12.1936$. 
Revista Zig-Zag. 1908. "Nuevo profesor de la Escuela de Bellas Artes”, N 176, Santiago de Chile, 5 de julio.

Richon Brunet, Ricardo. 1928. Revista Ilustrada, órgano de la Sociedad Nacional de Bellas Artes, octubre, año $1, \mathrm{~N}^{\circ} 1$.

Romera, Antonio. 1976. H istoria dela pintura chilena. Santiago de Chile: Editorial Andrés Bello.

Sanhueza, Jorge. 1956. “El primer Centenario de Virginio Arias”. Revista deArte Universidad de Chile, Instituto de Extensión de Artes Plásticas, N³, abrilmayo.

Vargas Rosas, Luis. 1953. “Evocación de Juan Francisco González”. Atenea, № 339.

Zamorano Pérez, Pedro Emilio. 1994. El pintor F. Alvarez de Sotomayor y su huella en América. La Coruña, España: Servicio de Publicaciones Universidad de La Coruña.

Zegers, Roberto. 1981. Juan Francisco González: M aestro de la pintura chilena. Santiago de Chile: Ediciones Ayer. 